\title{
RANCANG BANGUN APLIKASI PEMBELAJARAN BAHASA INGGRIS TENSES BERBASIS MULTIMEDIA
}

\author{
${ }^{1)}$ Popon Handayani, ${ }^{2}$ Sopian Aji \\ ${ }^{1,2)}$ STMIK NUSA MANDIRI JAKARTA \\ e-mail: sopian.sop@bsi.ac.id e-mail: poponaisyah88@gmail.com
}

\begin{abstract}
Sistem pembelajaran dengan menggunakan teknologi komputer sudah sangat banyak digunakan. Dikarekan perkembangan zaman yang sangat canggih, proses pembelajaran pun harus meningkat. Dimana teknologi tersebut menggunakan bahasa Inggris. Dan pelajaran Bahasa Inggris sangat menunjang untuk menguasai era globalisasi seperti sekarang,Pelajaran bahasa Inggris dikenalkan sejak anak usia dini hingga orang dewasa, Banyak sekali yang kesulitan dalam mempelajari tenses. Untuk itulah dilakukan pengembangan sarana pengantar pembelajaran untuk mempermudah dan mempersingkat waktu dalam memahami suatu pelajaran maka diperlukan sebuah aplikasi pembelajaran. Maka aplikasi pembelajaran tersebut dirancang dengan metode Microsoft Solution Framework (MSF).Aplikasi pembelajaran ini dibuat dengan menggunakan Macromedia Flash MX.diharapkan dapat membantu mengatasi permasalahan dalam mempelajari Tenses agar proses belajarnya lebih efektif.Aplikasi Pembelajaran ini melakukan observasi, dan wawancara. Peralatan yang digunakan dalam perancangan system ini menggunakan pemodelan UML Use Case Diagram meliputi Activity Diagram. Hasil dari penelitian ini adalah dihasilkan suatu program aplikasi pembelajaran Tenses yang sangat berguna untuk membantu para siswa maupun siswi untuk mempelajari ilmu Tenses.
\end{abstract}

Key Word: Aplikasi, Pembelajaran, Multimedia

\section{PENDAHULUAN}

Mata Pelajaran Bahasa Inggris sekarang ini sangalah penting. Karena merupakan kebutuhan dalam segala bidang baik pendidikan maupun pekerjaan bahkan dalam kehidupan sehari-hari. Salah satu permasalahan siswa pada mata pelajaran tersebut adalah sulitnya memahami Tenses yang sangat menyita pola fikiran dan waktu.

Hal ini disebabkan pelajaran bahasa Inggris di sekolah sangat membosankan, kurang menarik di mata siswa dan siswi. Maka pada penelitian ini akan dibangun sebuah aplikasi berbasis multimedia yang bertujuan memperkenalkan tenses pada siswa dan siswi dengan multimedia.
Salah satu perangkat lunak yang dikembangkan dan mendukung pembuatan aplikasi multimedia adalah Macromedia Flash MX. Perangkat tersebut dapat digunakan untuk membuat sebuah aplikasi berbasis multimedia.

Diharapkan dengan adanya aplikasi pembelajaran tenses ini siswa dan siswi dapat mulai belajar dengan penuh kesenangan dan daya nalar pun cepat tangkap.

\section{METODOLOGI PENELITIAN}

Teknik pengumpulan data yang digunakan penulis dalam pembuatan ini adalah 
a. Observasi

Observasi ke sebuah bimble yang bernama Permata Cerdas dengan melihat langsung kegiatan belajar mengajar dengan melakukan pengamatan,pencatatan,dan pengumpulan data guna mendapatkan data yang akurat.

\section{b. Wawancara}

Penulis mewawancarai langsung guru bimble tersebut tentang kegiatan belajar mengajar.

\section{c. Studi Pustaka}

Penulis melakukan pengumpulan data yang bersumber dari buku-buku, jurnal sebagai bahan refrensi yang dapat digunakan sebagai acuan yang bertujuan untuk mendapatkan panduan yang dibutuhkan.

\subsection{Microsoft Solution Framework (MSF)}

Microsoft Solutions Framework (MSF) adalah serangkaian prinsip, model, disiplin, konsep, dan tuntunan untuk membuat solusi teknologi informasi yang diciptakan oleh perusahaan Microsoft (Microsoft Corporation, 2003). Bisa dibilang MSF adalah sebuah Software Development Life Cycle (SDLC). Namun, MSF tidak hanya dapat diterapkan pada pembuatan aplikasi, MSF juga dapat diterapkan pada proyek- proyek IT lain seperti pembuatan infrastruktur dan jaringan. Hal ini karena MSF tidak hanya mencakup perekayasaan perangkat lunak namun hampir mencakup pembuatan sebuah proyek IT secara keseluruhan.

\subsection{Pembelajaran}

Pembelajaran merupakan suatu rangkaian peristiwa yang kompleks dan sistematis. Dalam peristiwa tersebut terjadi interaksi guru dan siswa dalam rangka perubahan sikap dan pola piker yang menjadi kebiasaan bagi siswa yang bersangkutan. Guru berperan sebagai pengajar dan siswa sebagai pelajar. Belajar dan mengajar adalah dua kegiatan yang bersamaan, tetapi memiliki maknayang berbeda.

Menurut Darsono (2002:24-25) secara umum menjelaskan pembelajaran sebagai "suatu kegiatan yang dilakukan oleh guru sedemikian rupa sehingga laku siswa dan siswi berubah ke arah yang lebih baik". Sedangkan secara khusus pembelajaran dapat diartikan sebagai berikut:

Teori Behavioristik mendefinisikan pembelajaran sebagai usaha guru (stimulus). Agar terjadi hubungan stimulus dan respon (tingkah laku yang diinginkan) perlu latihan, dan setiap latihan yang berhasil.

\subsection{Multimedia}

Multimedia adalah gabungan video, audio, grafik dan teks dalam suatu produksi berbasis computer yang dapat dialami secara interaktif. Untuk membuat sebuah media pembelajaran maka dibutuhkan beberapa objek multimedia. Objek-objek dalam multimedia diantaranya image, animasi, audio, video, dan interactive link

\section{HASIL DAN PEMBAHASAN}

Dalam proses belajar mengajar, seorang guru harus mempunyai kemampuan dalam mengelola kelas dan menciptakan suasana yang menyenangkan bagi siswa dan siswi agar tidak merasa bosan dan jenuh ketika proses belajar dan mengajar berlangsung. Disamping itu, hal yang harus diperhatikan oleh seorang guru adalah penggunaan media yang sesuai dan tepat untuk setiap materi yang disampaikan.

Karena penggunaan media yang tepat akan menunjang untuk pencapaian tujuan pembelajaran yang efisien dan efektif.

Media pembelajaran ini ditujukan untuk siswa dan siswi pada bimble.... 
Tujuan utama dari penelitian ini adalah untuk menyampaikan informasi tentang Tenses melaluui media audio dan visual, yang diharapkan mampu menjadi media pembelajaran yang interaktif, menarik,dan menambah semangat belajar dari siswa/siswi sehingga diharapkan ada perbaikan nilai dan pengetahuan siswa/siswi terkait Tenses.

Media pembelajaran interaktif ini dirancang dimulai dari tampilan awal, menu utama yang berisi Macam-macam Tenses, Penjabaran Tenses, Latihan Soal, dan keluar.

\subsection{Perancangan Sistem}

Perancangan Sistem merupakan tahapan analisis dari siklus pengembangan system pendefinisi dari kebutuhan-kebutuhan fungsional dan persiapan untuk rancangan system. Tahap perancangan system dilakukan oleh analisis system dan personilpersonil teknik lainnya.

\subsubsection{Use Case Diagram}

Use Case Diagram merupakan gambaran scenario dari interaksi antar user dengan system. Sebuah use case diagram menggambarkan hubungan antara actor serta kegiatan yang dapat dilakukannya terhadap aplikasi.

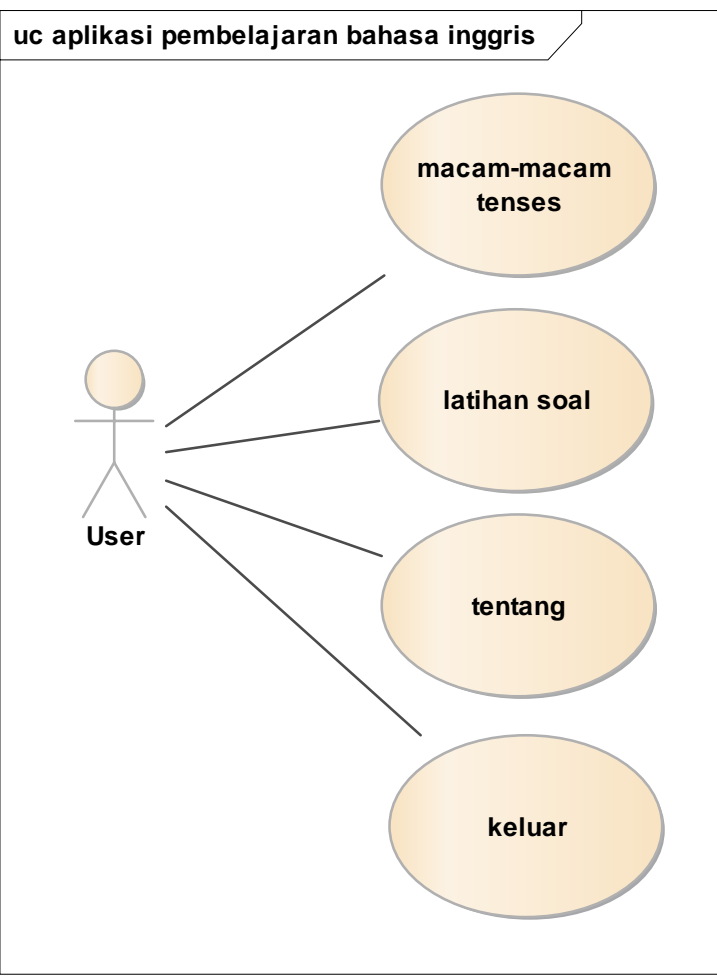

Gambar 1. Use Case Diagram Aplikasi Pembelajaran Bahasa Inggris Tenses

\subsubsection{Activity Diagram}

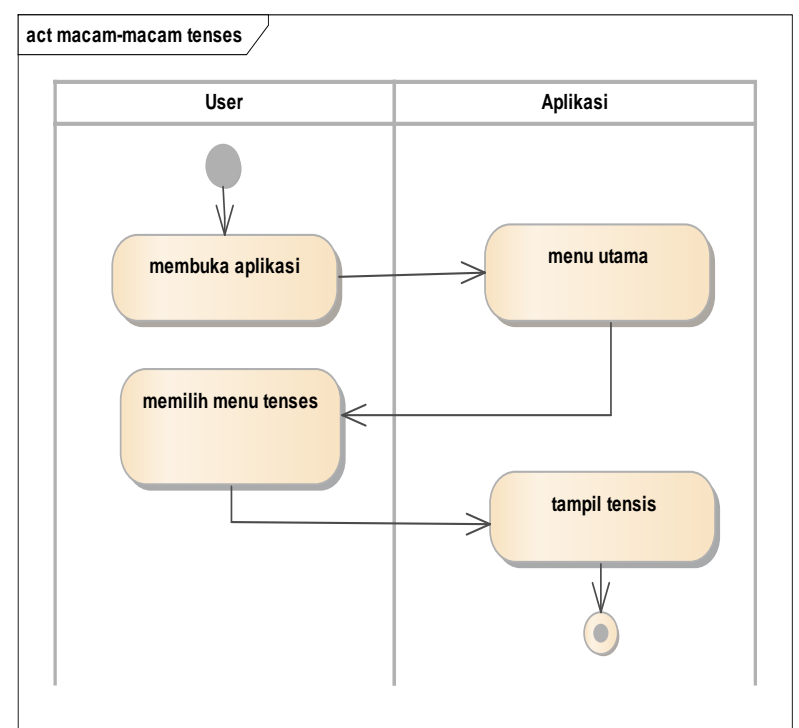

Gambar 2. Activity Diagram MacamMacam Tenses 


\subsubsection{Activity Diagram}

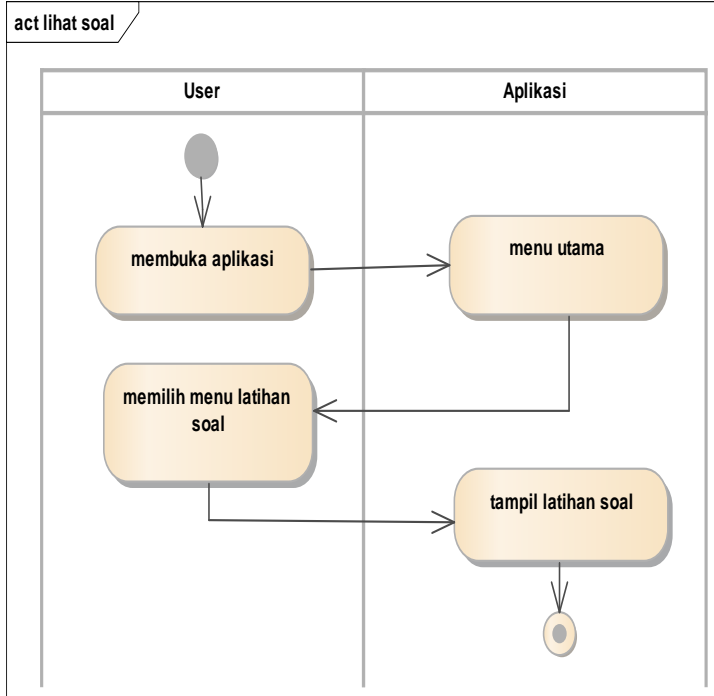

Gambar 3. Activity Diagram Lihat Soal

\subsection{Perancangan Interface}

Perancangan interface pada aplikasi ini terdiri dari halaman halaman Menu Utama, Halaman Menu Tenses, Halaman Latihan Soal, dan Halaman Tentang Program.

\section{Halaman Menu Utama}

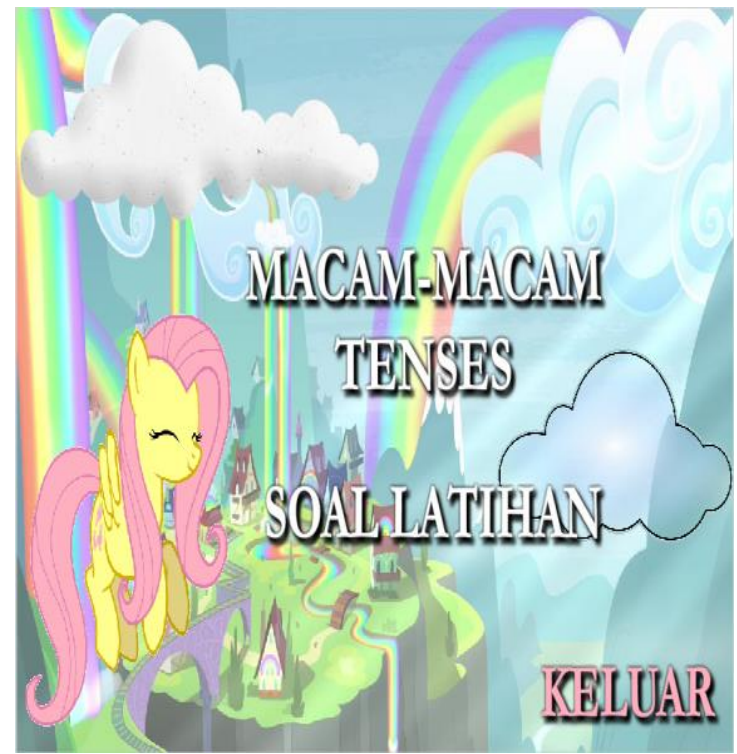

Gambar 4. Menu Utama
2. Halaman Menu Tenses

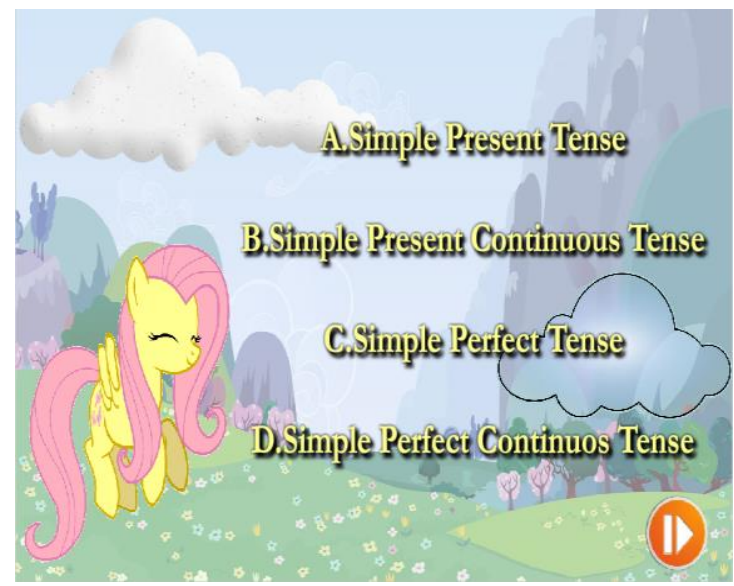

Gambar 5. Menu Tenses

\section{Halaman Latihan Soal}

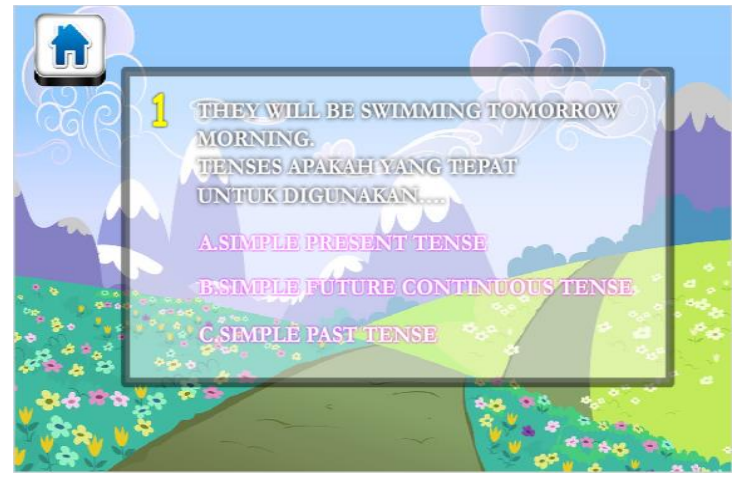

Gambar 6. Latihan Soal

\section{Halaman Setiap Tenses}

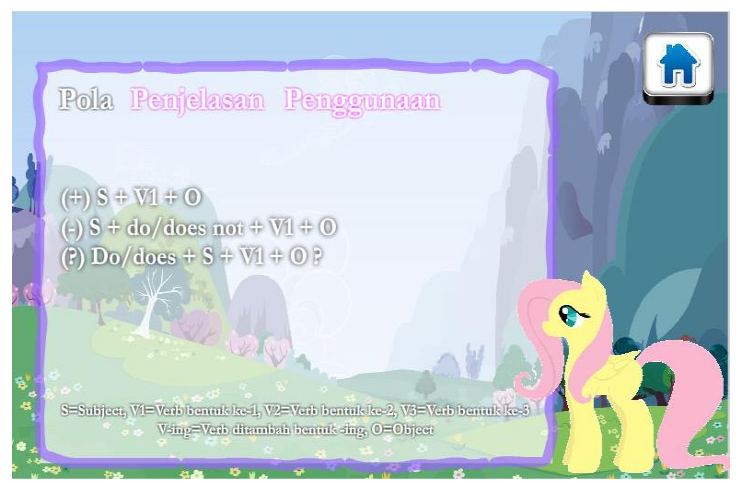

Gambar 7. Penjelasan Tenses

\subsection{Pengujian Program}

Pengujian Program dilakukan untuk mengetahui apakah pekerjaan pemrograman telah dilakukan dengan 
benar sehingga menghasilkan fungsifungsi yang dikehendaki. Pengujian juga dimaksudkan untuk mengetahui keterbatasan dan kelemahan system yang dibuat agar dapat sebisa mungkin dilakukan penyempurnaan.

\subsubsection{Pengujian Dengan White Box}

Aplikasi pembelajaran animasi interktif setelah dibuat selanjutnya dilakukan pengujian menggunakan teknik pengujian perangkat lunak yang meliputi pengujian white box dan black box. Menurut (Sugiyanto \& Y., 2011) dalam jurnalnya mengemukakan bahwa pengujian white box menggunakan struktur kontrol desain procedural (structural testing) untuk memperoleh test case. Adapun pengujian white box bertujuan untuk menjamin sistem melakukan fungsi dengan benar. Menurut (Sugiyanto \& Y., 2011) dalam jurnalnya mengemukakan bahwa "pengujian black box merupakan pengujian user interface kepada pengguna apakah sistem dapat dioperasikan atau tidak. Sedangkan pada black box dilakukan dengan memberikan data-data simple sebagai nilai masukkan dan dibandingkan dengan informasi yang dihasilkan, disebut juga pengujian berbasis scenario".

\section{Pengujian White Box}

Pengujian white box berfokus pada struktur kontrol program apakah semua statement pada program telah dieksekusi paling tidak sekali saja selama proses pengujian dilakukan dan semua kondisi logis telah dilakukan pengujian.

Mengukur kompleksitas siklomatis (pengukuran kuantitatif terhadap kompleksitas logis suatu program) dapat diperoleh dengan perhitungan seperti $\mathrm{V}(\mathrm{G})=\mathrm{E}-\mathrm{N}+2$ dimana $\mathrm{E}=\mathrm{Jumlah}$ edge grafik alir yang ditandakan dengangam barpanah,danN=Jumlah simpul grafik alir yang ditandakan dengan gambar lingkaran.
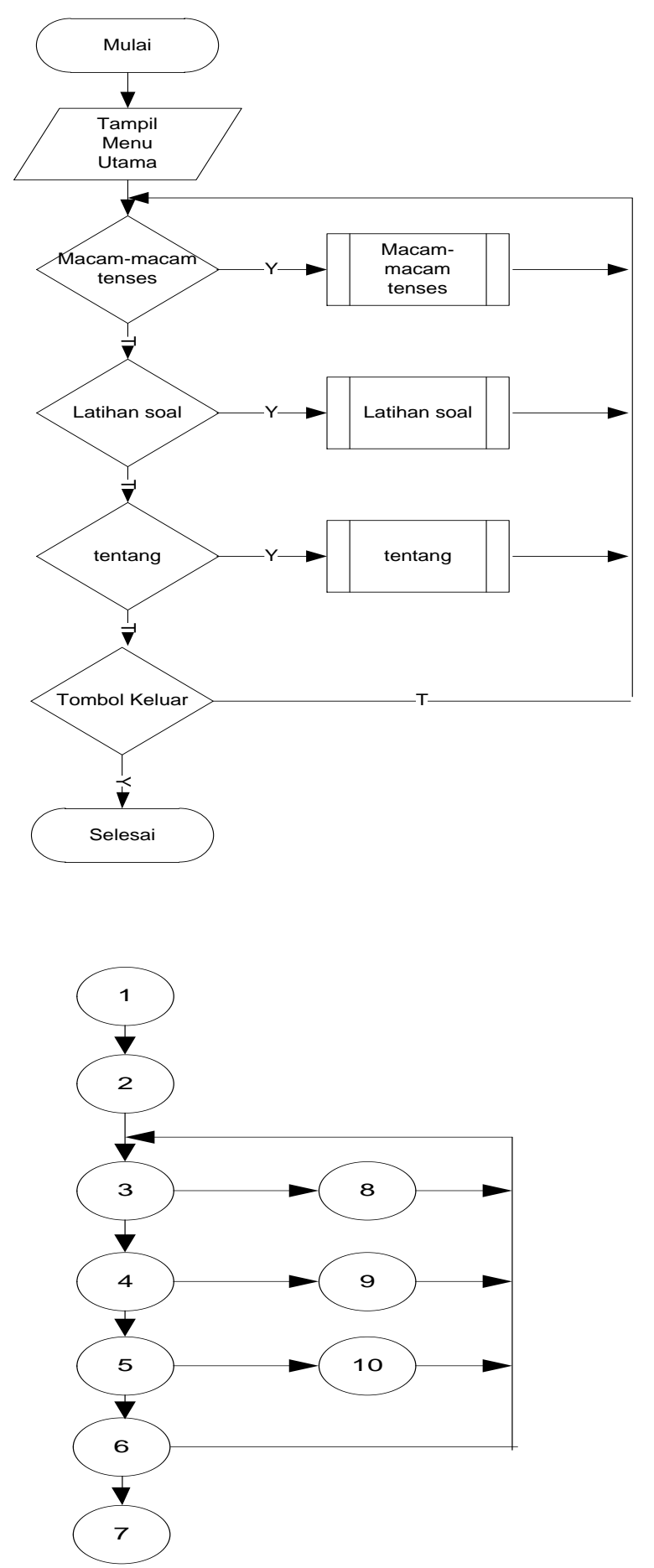

on(release $)\{$

loadMovie

("macamtenses.swf",0);

on(release $)\{$

loadMovie("latihan.swf",0);

on(release $)\{$ 
loadMovie("soal.swf",0); \}

on(release $)\{$

loadMovie("keluar.swf",0); \}

on(release $)\{$

fscommand("quit"); \}

Sehingga kompleksitas siklomatisnya $\mathrm{V}(\mathrm{G})=13-10+2=5$. Terdapat 5 jalur basic path yang dihasilkan dari jalur independent secara linier, yaitu:

\section{$1-2-3-8$}

\section{$1-2-3-4-9$}

\section{$1-2-3-4-5-10$}

\section{$1-2-3-4-5-6-3$}

\section{$1-2-3-4-5-6-7$}

Saat Aplikasi berjalan, maka akan terlihat bahwa dari salah satu basis set akan menghasilkan 1-2-3-4-5 dan akan terlihat bahwa simpul telah dieksekusi satukali. dari pengamatan ketentuan tersebut dan dari kelayakan software, sistem ini telah memenuhi syarat

\section{Pengujian Black Box}

Pengujian pada Black Box berikut ini akan menampilkan Pengujian pada menu utama saja, karena.keterbatasan halaman pada jurnal ini.

Tabel 2. Pengujian Menu Utama

\begin{tabular}{|l|l|l|l|}
\hline INPUT/ & \multicolumn{1}{|c|}{ PROSES } & $\begin{array}{c}\text { OUTPU } \\
\text { T/NEXT } \\
\text { STENT }\end{array}$ & $\begin{array}{c}\text { HAS } \\
\text { IL } \\
\text { PEN } \\
\text { GUJI } \\
\text { AN }\end{array}$ \\
\hline $\begin{array}{l}\text { Tombol } \\
\text { macam } \\
\text { tenses }\end{array}$ & $\begin{array}{l}\text { on(release) }\{ \\
\text { loadMovie("1 } \\
\text { huruf.swf",0); } \\
\}\end{array}$ & $\begin{array}{l}\text { Macam- } \\
\text { macam } \\
\text { tenses }\end{array}$ & $\begin{array}{l}\text { Sesu } \\
\text { ai }\end{array}$ \\
\hline
\end{tabular}

\begin{tabular}{|l|l|l|l|}
\hline $\begin{array}{l}\text { Tombol } \\
\text { lihat } \\
\text { soal }\end{array}$ & $\begin{array}{l}\text { on(release)\{ } \\
\text { loadMovie("2 } \\
\text { huruf.swf",0); } \\
\}\end{array}$ & $\begin{array}{l}\text { Soal } \\
\text { lahitan }\end{array}$ & $\begin{array}{l}\text { Sesu } \\
\text { ai }\end{array}$ \\
\hline tentang & $\begin{array}{l}\text { on(release) }\{ \\
\text { loadMovie("3 } \\
\text { huruf.swf",0); } \\
\}\end{array}$ & Tentang & $\begin{array}{l}\text { Sesu } \\
\text { ai }\end{array}$ \\
\hline $\begin{array}{l}\text { Tombol } \\
\text { Keluar }\end{array}$ & $\begin{array}{l}\text { on (release)\{ } \\
\text { fsco } \\
\text { mmand("quit" } \\
\text { ); }\end{array}$ & Keluar & $\begin{array}{l}\text { Sesu } \\
\text { ai }\end{array}$ \\
\hline
\end{tabular}

\section{KESIMPULAN}

Berdasarkan aplikasi yang telah dibuat oleh peneliti maka dapat disimpulkan yaitu:

1. Aplikasi Pembelajaran Tenses dengan Macromedia Flas MX berhasil dibuat.

2. Aplikasi Pembelajaran Tenses dapat digunakan sebagai alternatif pembelajaran Tenses yang menyajikan informasi Tenses.

3. Aplikasi pembelajaran Tenses dapat dilihat di Aplikasi Komputer.

\section{DAFTAR PUSTAKA}

Fiftrin Noviyanto (2008). Membangun Sistem Pembelajaran Pengenalan Bentuk Untuk Anak Berbasis Multimedia Dan Game Interaktif, INFORMATIKA 59-167.

Bunga Pratiwi, Herlawati (2015). Animasi Interaktif Pengenalan Pembelajaran Sistem Peredaran Darah Pada SD Widya Bhakti Bekasi, Bina Insani ICT Journal,15-32. 
Ryandi Surya Gautama, Insani Kasih, Iis Pradesan. Rancang Bangun Aplikasi Pembelajaran Bahasa Inggris Berbasis Multimedia Pada Bimble Excellence, JURNAL STMIK GI MIDP, 1-10.

Echols, J.M., Dan Shadily, H.(Eds), (1989)

KamusInggris-Indonesia", PT.Gramedia.Pustaka Umum, Jakarta.

Hasannudin (2010). Pemrograman Actionscript Dengan Flash 5 Dan Aplikasinya. Yogyakarta:Penerbit Andi..

Rizki, Soetam (2011). Konsep Dasar Perangkat Lunak. Jakarta: Prestasi Pustaka Publisher. 